\title{
An Investigation of Demotivators for Online Resources
}

\author{
Shih-hsien Yang
}

\begin{abstract}
Previous studies have investigated student language learning by using technical tools such as, websites, e-mails, and discussion forums. Most reports showed that e-learning gives students flexible time and space for self-learning. However, few research findings showed the opposite results of student e-learning. Demotivation is another issue in the field of language learning. Instead of trying to find out what motivates students to learn, this study investigated what demotivators students might experience while using online resources. The results showed that learning contents and future career implications (the lack of intrinsic motivation) were the major two demotivating factors for online resources.
\end{abstract}

\section{Index Terms-Demotivation, e-learning, online resources}

\section{INTRODUCTION}

\section{A. Technology and Internet for Language Learning}

The use of the computer and internet is becoming common in the educational and business realms. In contrast to the traditional environment, the use of the computer and internet offers greater opportunities for interactivity and learner control [1]. More and more educators and language teachers integrate the Internet with language teaching, defined as E-learning. Unlike the traditional face-to-face meetings or discussions, the e-learning provides both teachers and students with an alternative avenue to foster their personal knowledge development through meaningful negotiation and communication [2], [3]. The most commonly used programs and tools in the past few years for language teachers were e-mail systems, discussion forums, and Internet chat rooms [4].

Many studies show that language learners can be difficult to be motivated when it comes to traditional English reading [1], [5]. Studies show that Internet access can motivate students to learn [6], [7], by which language teachers can ask students questions, share viewpoints, encourage students to discuss issues and express their concerns on a designed blog or a discussion forum [8]. In general, whether by reading or practicing writing the texts in a computer-supportive environment, most learners show higher learning motivation [9].

Taking the blogging as an example, teachers can provide many learning resources in the blog by sharing online learning websites with students. Teachers might share online testing sites to allow students more time to practice certain tests and exams. In addition, teachers can make

Manuscript received May 17, 2012; revised June 13, 2012.

Shih-hsien Yang is with Department of Applied Foreign Languages, National Formosa University, YunLin, Taiwan ( email: shiyang@nfu.edu.tw). good use of other sites embedded with audio and visual materials to enhance students' learning motivation [8]. As a result, students gain more knowledge through links to prosperous sites. The inclusion of these websites also allows for self-directed exploration within the topic [10].

The advantages of the e-learning can be further illustrated. The e-learning does not merely establish scaffolding for beginners, but allow students to learn from multiple perspectives or receive support from advanced students. In addition, the e-learning creates a relatively learner-centered environment that allows students to learn at their own pace [10]. In summary, the e-learning (e.g. chat rooms or forums) can be treated as language exchange classrooms. Tsai [11] concluded four major attributes of the online learning environment: (1) flexible time and space, (2) indirect social interaction, (3) abundant information resources, and (4) dynamic learning interfaces which summarize again the advantages of online learning.

\section{B. Self E-learning and Demotivating Factors}

With high degrees of the freedom and abundant resources in the e-learning environment [11], [12], individual learners must have self-awareness, self-control, or other traits while learning in the e-learning environment [13]. Collis and Meeuwsen [14] point out some key factors for the e-learning, including articulation, reflection, planning skills, study skills, self-evaluation, and so on. In most studies, there were positive feedbacks from teachers who employed the computer for language learning. However, when referring to the issue of self-learning, there were only few reports and results were two-sided. In addition, the language classroom is considered a microcosm of the world with students coming from different backgrounds and cultures, with different learning styles and personalities, and different language skills. Therefore, how to deal with students coming from different cultures with different learning styles also became an issue when discussing about the learning motivation [15].

Over the past decade, researchers and schools tried hard to find out how to motivate students to learn and what influences students' motivations while learning the target language [16]-[18]. Why do most students lose their motivation to learn the target language? Many researchers indicated that demotivation could be the main factor for most language learners. Demotivation could be both internal factors such as lack of confidence and external factors such as test scores. The previous studies conducted in Japan involved with the populations from elementary school students to university students. The results from those studies showed different demotivating factors among different groups of learners. The issue of demotivation has less been embarked on in the previous studies. Therefore, this study aimed to investigate what the demotivating 
factors could be when it comes to self e-learning in central Taiwan's district on students at a college level.

\section{THE STUDY}

\section{A. Participants}

The participants of this study were 117 second-year students in the Department of Finance at one University of Science and Technology in central Taiwan enrolling in the Advance English course. There were 17 male students and 100 female students.

\section{B. Instrument}

Two questionnaires were employed in this study. The first one was the online learning strategies scale adapted from Tsai [11]; the other one was the demotivation questionnaire modified from Kikuchi \& Sakai [18]. The questionnaire of online learning strategies scale was categorized into five subscales with 20 questions, involving motivation, self-monitoring, Internet literary, Internet anxiety, and concentration. The demotivation questionnaire consisted of 205 -level Likert scale questions as well. The 20 questions were divided into five different categories: (1) learning contents and materials, (2) teachers' competence and teaching styles, (3) inadequate school facilities, (4) lack of intrinsic motivation, and (5) test scores.

Semi-structured interviews were conducted after the demotivation questionnaire was done. Four interviewees were selected from students who scored higher and lower in the midterm exam. The length of each interview lasted for one hour and was recorded for future analysis.

\section{Procedure}

During the semester, a teacher introduced many online resources such as Randall's ESL Cyber Listening Lab, Internet Chat rooms, and Youtube.com for students to do self-learning both in class and out of the class. During the course, the teacher would go through each chapter from the textbook. The chapters were themes related to business conversations such as marketing presentations and trading requests. Later in the class, the teacher employed some online websites and software for students to practice English skills such as listening practice. The teacher used some audio resources from the Randall's ESL Cyber Listening Lab and gave students time to practice in groups. Sometimes, the teacher assigned the students to look for some video clips based on different learning topics from Youtube.com and ask the students to show the clips they found. The teacher also suggested several websites for the students to do self-learning at home.

After the students had been explored several online resources, the questionnaire of online learning strategies scale was collected in the middle of the semester. The demotivation questionnaire was distributed one week before the semester ended. Parts of the online learning activities were included in students' midterm exam. Semi-structured Interviews were conducted in Chinese after the demotivation questionnaire was done. Four interviewees were selected from students who scored higher and lower in the midterm exam. The interview data was recorded and later translated into English.

\section{Research Questions}

This study focused not only the effectiveness of online resources but also the demotivation of students' target language learning. Two research questions were discussed in the following:

1) What were the major demotivating factors in English class for using online resources?

2) To what degree do higher achievement students differ from lower achievement student in terms of demotivation of using online resources?

\section{E. Data Analysis}

The analysis explored the key factors of students' demotivation of using online resources. Descriptive statistics of students' responses on 20 questions were calculated and presented for statistical analysis, which concerning about learning contents and materials, teachers' competence and teaching styles, inadequate school facilities, lack of intrinsic motivation, and test scores were presented respectively.

For interview data, Lincoln and Guba's [19] constant comparative method was implemented in coding the data analysis. The interviews were transcribed and analyzed. Themes and issues collected from the interviews were compared to the questionnaire results as well.

\section{RESULTS}

Table I revealed five subcategories of learning strategy in the online learning. Results showed that most students were attracted and excited by the online learning. However, regarding the self-monitoring, most students had hard time planning or arranging their time of learning online. It was believed that most students only used the resources which the instructors provide in class. When they were asked to practiced these resources after class, most students spent time watching movies, shopping, auctioning or texting with friends but not learning the target language.

\begin{tabular}{|c|c|c|}
\hline Subscale & Question & Mean \\
\hline \multirow[t]{5}{*}{ Motivation } & 1. I am attracted to online learning & $4.12(1.19)$ \\
\hline & 2. I am excited about learning on the Internet & $4.31(1.16)$ \\
\hline & 3. I like online learning & $4.22(1.13)$ \\
\hline & 4. I think online learning is convenient & $4.45(1.25)$ \\
\hline & 5. I am curious about online learning & $3.58(1.18)$ \\
\hline \multirow[t]{5}{*}{ Self-monitoring } & 6. I make study plans for online learning & $2.89(0.93)$ \\
\hline & 7. I am able to use online learning aids & $3.99(1.24)$ \\
\hline & 8. I change my online learning plans when & \\
\hline & necessary & $3.10(1.15)$ \\
\hline & 9. I am able to take online notes using word & \\
\hline & & \\
\hline \multirow[t]{5}{*}{ Internet Literary } & 10. I am able to send and receive emails & $5.00(0.10)$ \\
\hline & 11. I am able to search for information online & $4.58(0.93)$ \\
\hline & 12. I understand the differences between online & \\
\hline & learning and traditional learning & $4.06(1.01)$ \\
\hline & 13. I am able to download files from the Internet & $5.00(0.10)$ \\
\hline \multirow[t]{4}{*}{ Internet Anxiety } & 14. Online learning makes me feel frustrated & $4.32(0.95)$ \\
\hline & 15. I do not progress in online learning & $2.33(0.58)$ \\
\hline & 16. I am worried about my achievements in online & \\
\hline & learning & $3.66(1.29)$ \\
\hline \multirow[t]{5}{*}{ Concentration } & 17. I am easily distracted by music or MSN & $4.05(1.11)$ \\
\hline & 18. I avoid anything that interrupt my online & \\
\hline & learning & $2.89(1.42)$ \\
\hline & 19. I can not focus on my online learning & $3.99(1.12)$ \\
\hline & 20. I make good use of my time for online learning & $2.56(1.22)$ \\
\hline
\end{tabular}

Adapted from Tsai (2009) 
From Table I, it was clear that online learning provided a higher motivation for students to learn. Four selected interviewees also pointed out that Taiwanese students tended to be shy, especially female students. It was hard for them to talk freely or express their opinions in class. They thought that most students were passive even when teachers were asking for volunteers for some activities or answers. Therefore, they thought it was a good design for the teacher to employ the e-learning so that some shy students might have chances to express their thinking on certain forums, chat rooms or blogs.

From the collected data, self-monitoring and concentration were two major issues of demotivation when students were using online resources. The resources the instructor provided were good for in-class activities, but not for students' self at-home learning without the instructor's supervision. The students tended to become lazy while using at-home e-learning.

Table II showed five major demotivors students had for their learning. It presented the five major demotivators students might have for their learning with 20 questions modified from the survey of Kikuchi \& Sakai [20]. Most questions were trying to find out why students were still lack of motivations of learning the target language even when accompany with technology and online resources.

TABLE II : FACTOR ANALYSIS OF DEMOTIVRATION FOR ONLINE LEARNING

\begin{tabular}{|c|c|}
\hline Factor 1: Learning contents and materials & Mean SD \\
\hline 1. Most of the sites focused on grammar & $3.55(1.12)$ \\
\hline 2. English passages in the websites were too long & $4.24(1.02)$ \\
\hline 3. A great number of online readings were assigned & $2.35(1.18)$ \\
\hline 4. English sentences on the websites were hard to interpret & $3.98(1.32)$ \\
\hline 5. Online resources were not interesting & $1.87(0.96)$ \\
\hline \multicolumn{2}{|l|}{ Factor 2: Teachers' competence and teaching styles } \\
\hline 6. Teachers' online resources were out of date & $3.21(1.01)$ \\
\hline 7. Teachers only gave little time for online learning & $2.89(1.23)$ \\
\hline 8. Teachers did not include online learning for exams & $4.08(0.95)$ \\
\hline 9. Teachers did not trace students' online learning progress & $4.58(1.02)$ \\
\hline 10. the content of sites was not appropriate & $3.63(1.35)$ \\
\hline \multicolumn{2}{|l|}{ Factor 3: Inadequate school facilities } \\
\hline 11. computer equipment was outdated & $1.88(0.88)$ \\
\hline 12. Visual materials (Video and DVDs) were boring & $1.56(0.53)$ \\
\hline 13. The Internet was slow & $1.32(0.68)$ \\
\hline 14. Language lab equipment was not enough for everyone & $3.18(1.03)$ \\
\hline \multicolumn{2}{|l|}{ Factor 4: Lack of intrinsic motivation } \\
\hline 15. Extra online learning wasted my time & $2.95(0.23)$ \\
\hline 16. Most people around me did not practice online learning & $4.02(1.22)$ \\
\hline 17. Online learning was adding my study load & $3.65(1.01)$ \\
\hline 18. English can not be applied for my future career & $4.05(1.25)$ \\
\hline 19. I have no purpose of using online resources & $3.64(1.11)$ \\
\hline \multicolumn{2}{|l|}{ Factor 5: Test scores } \\
\hline 20. 1 got low scores on tests & $4.13(1.08)$ \\
\hline
\end{tabular}

Modified from Kikuchi \& Sakai (2009)

From the Table $\Pi$, it was obvious that students were overwhelmed by extra online resources because English passages in the websites were too long (mean=4.24), and they tended not to practice the online resources outside of the class because teachers did not trace students' online learning progress $($ mean $=4.58)$ and/or teachers did not include online learning for exams (mean=4.08). In addition, the lack of intrinsic motivation might be the biggest factor for demotivor for self e-learning. Two possible demotivators in that category were that most students did not do well enough on their exams (mean=4.13) and they thought they might not apply their learning in the future occupations (mean=4.05).

The second research question from this study tried to probe into whether there were differences in demotivating factors between low achievers and high achievers. Based on the additional interviews from the selected students, learning contents and materials and teachers' competence and teaching styles were the three major demotivators for the proficient students. They indicated that the learning activities designed by some teachers were really boring. In addition, the materials and contents, which they had learned in high schools, were too easy. On the contrary, for those two low achievers, low intrinsic motivation and poor performance in the test were the two major demotivators. Many participants expressed that they will not find jobs related to English speaking ones after graduating from the university. Most participants thought that many employers in Taiwan do not necessarily require people who were good at English. What's worse, their poor test scores at school decreased their learning motivation.

\section{CONCLUSION}

This study showed that learning contents and future career implications (the lack of intrinsic motivation) were the major demotivating factors for the participants of second-year students in this department. It is believed that due to the fact that most job requirements in Taiwan do not include English ability, therefore, learners do not perceive the immediate needs for learning the language. What's worse, sometimes the learning contents and themes are overlapping for different subjects. Those are the main factors that decrease students' learning motivation.

Based on the findings of this study, suggestions for English education in similar contexts were presented as follows:

1) Teachers need to employ the e-learning in the curriculum and take grading into consideration for students' participation. Otherwise, most students would loose the motivation while doing the self e-learning.

2) For high and low achievers, there were different demotivators in learning English. While teachers assigned websites for self-learning, different levels of learning contents should be introduced to the students based on their English proficiency.

3) Teachers could list out the possible occupations and requirements for students to keep and enhance their job competence as well as continuously encourage them to become autonomous and independent learners.

\section{REFERENCE}

[1] R. Kozma, "Learning with media," Review of Educational Research, vol. 61, no. 2, pp. 179-211, Summer, 1991

[2] T. C. Ahern, J. A. Thomas, M. K. Tallent-Runnels, W.Y. Lan, S. Cooper, X. Lu and C. Jacqui, "The effect of social grounding on collaboration in a computer-mediated small group discussion,' Internet and Higher Education, vol. 9, pp. 37-46, 1st Quarter, 2006

[3] G. Lord and L. L. Lomicka, "Developing collaborative cyber communities to prepare tomorrow's teachers," Foreign Language Annals, vol. 37, no. 3, pp. 401-417, Oct. 2004 
[4] B. Godwin-Jones, "Emerging technologies: Blogs and Wikis: environments for on-line collaboration," Language Learning \& Technology, vol. 7, no. 2, pp. 12-16, May 2003

[5] [5] B. Ho and J. C. Richards, "Reflective thinking through teacher journal writing: myths and realities," Prospect, vol. 8, pp. 7-24, Dec. 1993.

[6] J. Rodzvilla, We've got blog: how weblogs are changing our culture. Perseus Publishing, Cambridge, MA, 2002.

[7] G. M. Stiler and T. Philleo, "Blogging and blogspots: an alternative format for encouraging reflective practice among preservice teachers," Academic Research Library, vol. 123, no. 4, pp. 789-798, Jun. 2003

[8] W. Richardson, Blogs, wikis, podcasts, and other powerful web tools for classrooms. Corwin Press, 2005.

[9] B. Godwin-Jones, "Emerging technologies: Web-writing 2.0: enabling, documenting, and assessing writing online," Language Learning \& Technology, vol. 12, no. 2, pp. 7-13, Jun. 2008

[10] L. Efimova and S.Fiedler, Learning webs: learning in weblog networks. In P. Kommers, P. Isaias, \& M. B. Nunes (Eds.), Proceedings of the IADIS International Conference Web Based Communities 2004 Lisbon, Portugal: IADIS Press, 2003, pp.490-494.

[11] C. Tsai, "Conceptions of learning versus conceptions of web-based learning: The differences revealed by college students," Computers \& Education, vol. 53, pp. 1092-1103, Jun. 2009.

[12] M. J. Tsai and C. C. Tsai, "Student computer achievement, attitude and anxiety: The role of learning strategies," Journal of Educational Computing Research, vol. 28, pp. 47-61, 2003

[13] R. J. Chu and C. C Tsai, "Self-directed learning readiness, Internet self-efficacy, and preferences for constructivist Internet-based learning environments among higher aged adults," Journal of Computer Assisted Learning, vol. 25, pp. 489-501, Jul. 2009.
[14] B. Collis and E. Meeuwsen, Learning to learn in a WWW-based environment. In D. French, C. Hale, C. Johonson, \& G. Farr (Ed.), Internet-based learning - An introduction and framework for higher education and business.. New York: Kogan, 1999, pp. 25-46.

[15] S. L. Mckay, Agendas for second language literacy. New York: Cambridge University Press, 1993.

[16] J. Falout and M. Maruyama, "A comparative study of proficiency and learner demotivation," The Language Teacher, vol.28, pp. 3-9, Aug. 2004.

[17] O. Ikeno, "Motivating and demotivating factors in foreign language learning: A preliminary investigation," Ehime University Journal of English Education Researchm, vol. 2, pp. 1-19, 2002.

[18] K. Kikuchi, "Listening to our Learners' Voices: What Demotivates EFL High School Students?" Language Teaching Research, vol. 13, no.4, pp. 453-471, Oct. 2009.

[19] Y. S. Lincoln and E. G. Guba, Naturalistic inquiry. Beverly Hills, CA.: Sage Publications, 1985.

[20] K. Kikuchi and H. Sakai, "Japanese learners' demotivation to study English: A survey study,” JALT Journal, vol. 31, no. 2, pp. 183-204, Nov. 2009

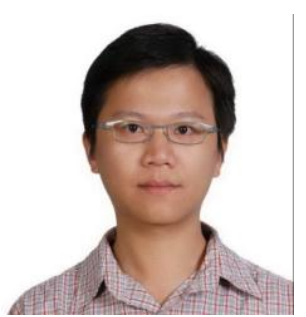

Shih-hsien Yang is an associate professor in the Applied Foreign Languages Department at National Formosa University in Taiwan. His research interests are computer assisted language learning and teacher professional development. 